\title{
Pathway concepts experiment for head-down synthetic vision displays
}

\author{
Lawrence J. Prinzel III ${ }^{\mathrm{a}}$, Jarvis J. Arthur III ${ }^{\mathrm{a}}$, Lynda J. Kramer ${ }^{\mathrm{a}}$, Randall E. Bailey ${ }^{\mathrm{a}}$ \\ ${ }^{a}$ NASA Langley Research Center, 24 West Taylor Street, Hampton, VA, USA 23681-0001
}

\begin{abstract}
Eight 757 commercial airline captains flew 22 approaches using the Reno Sparks 16R Visual Arrival under simulated Category I conditions. Approaches were flown using a head-down synthetic vision display to evaluate four tunnel ("minimal", "box", "dynamic pathway", "dynamic crow's feet") and three guidance ("ball", "tadpole", "follow-me aircraft") concepts and compare their efficacy to a baseline condition (i.e., no tunnel, ball guidance). The results showed that the tunnel concepts significantly improved pilot performance and situation awareness and lowered workload compared to the baseline condition. The dynamic crow's feet tunnel and follow-me aircraft guidance concepts were found to be the best candidates for future synthetic vision head-down displays. These results are discussed with implications for synthetic vision display design and future research.
\end{abstract}

Keywords: Synthetic Vision, Head-Down Displays, Aviation Safety, Tunnel, Pathways, Guidance Symbology

\section{INTRODUCTION}

The worldwide commercial aviation major accident rate is low and has remained nearly constant over the past two decades. However, the demand for air travel is expected to increase over the coming two decades, more than doubling by 2017. Without an improvement in the accident rate, such an increase in traffic volume would lead to a projected 50 or more major accidents a year worldwide - a near weekly occurrence. Given the very tragic, and damaging effects of a single major accident, this situation would deliver an unacceptable blow to the aviation system. Dramatic steps, therefore, are needed to ensure the unquestioned safety for the traveling public that has made flying the safest mode of transportation.

\subsection{NASA Synthetic Vision Systems}

To help meet national aviation safety goals will require mitigating or eliminating the etiologies of accidents. A significant factor involved in many commercial and general aviation accidents is limited visibility. The ability of a pilot to ascertain critical information through visual perception of the outside environment can be limited by various weather phenomena, such as rain, fog, and snow. Since the beginning of flight, the aviation industry has developed various devices to overcome these low-visibility limitations. These include attitude indicators, navigation aids, Instrument Landing Systems (ILS), moving map displays, and Terrain Awareness and Warning Systems (TAWS). All of the aircraft information display concepts developed to date, however, still require the pilot to continuously perform information acquisition and decoding to update and maintain their mental model in order to "stay ahead" of the aircraft when outside visibility is reduced. What this means is that pilots still have to interpret the "coded" (Theunissen, 1997) information and match it to the outside world.

NASA's Aviation Safety Program (AvSP) initiated a new research project to develop technologies to help overcome safety problems associated with limited visibility. The NASA Synthetic Vision System (SVS) project is based on the premise that better pilot situation awareness during low visibility conditions can be achieved by reducing the steps required to build a mental model from disparate pieces of data through the presentation of how the outside world would look to the pilots if their visibility were not restricted. New technological developments in navigation performance, low-cost attitude and heading reference systems, computational capabilities, and graphical displays allow for the prospect of SVS displays for virtually all aircraft classes. SVS display concepts employ computer-generated terrain imagery, on-board databases, and precise position and navigational accuracy to create a three dimensional perspective presentation of the outside world, with necessary and sufficient information and realism, to enable operations equivalent to those of clear, unlimited visibility regardless of the outside weather condition. The SVS concept includes the intuitive display of intended flight path by tunnel or pathway-in-the-sky presentations. When coupled with a synthetic view of 
the world, the spatially integrated depiction of the intended aircraft flight path and its relation to the world provides an easily interpretable display of flight-critical information for the pilot (Figure 1). The safety outcome of SVS should be a reduction, or even prevention, of controlled-flight-into-terrain (CFIT), which is the single greatest contributing factor to fatal worldwide airline and general aviation accidents (Boeing, 1996; Prinzel et al., 2002; 2003; 2004). Other safety benefits potentially include reduced runway incursions and loss-of-control accidents (Williams et al., 2001) in addition to significant operational and economic benefits (Hemm, 2000).
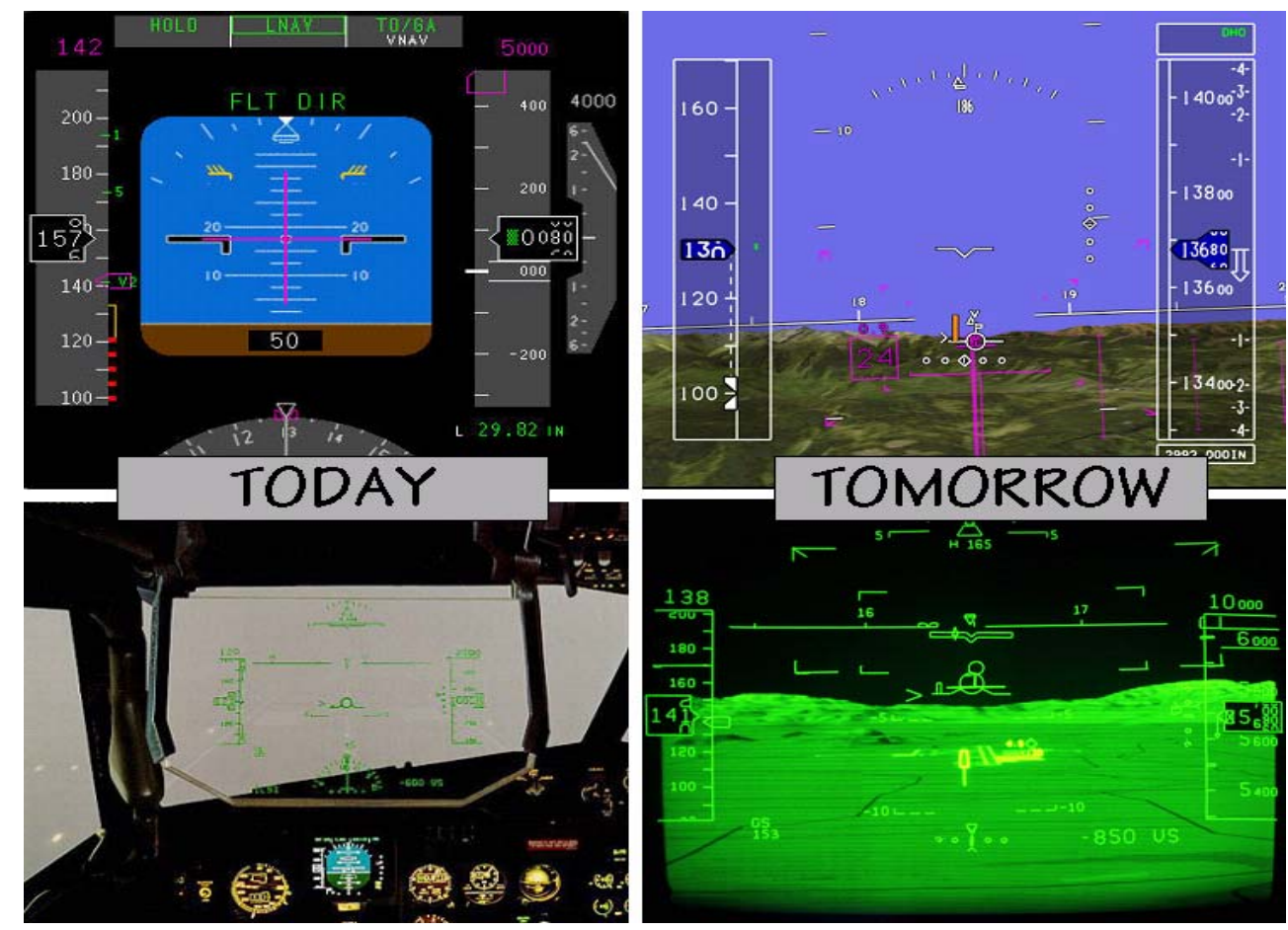

Figure 1. Head-Down and Head-Up Future Synthetic Vision Displays

\subsection{Safety Benefits of SVS}

It is highly unlikely that conventional display concepts can significantly increase safety as new functionality and new technology cannot simply be layered onto previous design concepts because current system complexities are already too high (Theunissen, 1997). Better human-machine interfaces require a fundamentally new approach. One such approach applies the fundamental advantage of perspective flight path displays relative to conventional displays. Rather than commanding the pilot what to do, or at best showing only the error with respect to the desired trajectory, guidance and navigation displays can now provide information about the margins within which the pilot is allowed to operate. These displays are augmented to show such information as spatial constraints and terrain constraints, rather than just showing conventional flight director commands, which only indicate an error, seemingly independent of the actual constraints. These additional display elements provide guidance that does not force the pilot to apply a continuous compensatory control strategy. Only in this way can human flexibility be exploited. This is a fundamental difference between current and SVS displays - that synthetic vision embodies the concept of "human-centered" design by providing natural versus coded information to the pilot (Theunissen, 1997).

Because SVS displays are posited to provide both natural and coded information to the pilot, better pilot spatial situation awareness during low visibility conditions can be achieved. Synthetic vision technology will allow the issues associated with limited visibility to be solved with a vision-based solution, making flight conditions the equivalent of day unlimited ceiling and visibility, which will help improve situation awareness, lower workload, and support proper development of pilots' mental models. Therefore, SVS can have a most significant impact on improving aviation safety, 
as limited visibility has often been cited as the single greatest contributing factor in fatal worldwide airline and general aviation accidents (Boeing, 1998).

Consider that one of the major classifications of aviation accidents involving visibility issues is CFIT, and that CFIT is the greatest cause of aviation fatalities. A CFIT accident is defined as "one in which an otherwise-serviceable aircraft, under control of the crew, is flown (unintentionally) into terrain, obstacles or water, with no prior awareness on the part of the crew of the impending collision" (Wiener, 1977). Enders, et al., (1996) noted that worldwide, the chances of CFIT accidents are 5 times higher in non-precision approaches. SVS could have a significant impact in ameliorating the incidence of this accident category (Arthur et al., 2003; Prinzel et al., 2003). For commercial transport aircraft, instant recognition and correction of visibility-induced errors may eliminate CFIT. If accurate positioning information of other traffic were incorporated into the system, SVS could also help to eliminate runway incursions. For general aviation aircraft, a lower cost implementation of such a system could help to prevent visibility-induced loss-of-control accidents by providing an intuitive, easy-to-fly visual reference for Visual Meteorological Conditions (VMC)-like operations in Instrument Meteorological Conditions (IMC). It would also be anticipated that SVS technology could serve to increase national airspace system capacity by providing the potential for VMC-like operations more of the time (Hemm, 2000; Kramer, Prinzel, Arthur, \& Bailey, 2003).

\subsection{Research Challenges to Synthetic Vision}

Although there is significant potential for SVS to help meet national aviation goals, there are still considerable research challenges. To identify these challenges, a workshop resulting in a concept of operations for commercial and business aircraft was held in early 2000 (Williams, et al., 2001). A similar workshop was hosted that focused on general aviation aircraft. The focus of these events was to obtain wide ranging input on the benefits and features which synthetic vision might incorporate. This meeting included representatives from NASA, Department of Defense, FAA, industry, professional organizations, airlines, aircraft and avionics manufacturers, airports, and academic institutions. The result of the workshop was an identification of research issues that need to be explored in developing SVS display concepts. Primary among them, expressed as questions, are:

- How can an SVS display be retrofitted into an aircraft class that has limited real-estate display space?

- What are the perceptual issues involved with minification and increased field of views on smaller SVS displays?

- What is the best way to present synthetic terrain to enhance situation awareness?

- What is the best way to present tunnel and guidance symbology on a synthetic vision display?

- Can an SVS display improve SA and reduce workload?

- What are the cognitive issues that may affect safety of flight when pilots fly a "compelling" synthetic vision scene?

- What is the best way to display the synthetic vision scene and what are the database and sensor requirements to ensure the integrity of a synthetic vision system?

To date, a significant amount of human factors research has been conducted at the NASA Langley Research Center to investigate these issues (e.g., Arthur et al., 2003; Kramer et al., 2003; Prinzel et al., 2001; 2002; 2003; 2004). Many of these issues have been resolved, but several significant ones still remain. Among them are issues concerning how best to design tunnel and guidance symbology for integration as part of synthetic vision head-down and head-up displays.

\subsection{Advanced Pathway Displays}

Although avionics have advanced significantly since Jimmy Doolittle flew the first "blind" flight in 1929, Theunissen (1997) noted that significant increases in aviation safety are unlikely to come by extrapolating from current display concepts. He further stated that, "new functionality and new technology cannot simply be layered onto previous design concepts, because the current system complexities are already too high. Better human-machine interfaces require a fundamentally new approach" (1997; p.7). Bennet and Flach (1994) argued that such an approach should not focus on development of "idiot-proof" systems because of the infinite potential problem space, but rather should provide the pilot information that would enable successful solution sets to be generated. These displays should present continuous information about spatial constraints rather than command changes to reduce error states, and should show error margins that depict the bounds that the pilot may safety operate in contrast to the compensatory control strategy required by 
current cockpit instruments. This may be accomplished through the use of "pathway" or "tunnel" displays. Several NASA projects, including SVS, are exploring the use of flight path depiction as key parts of the human-computer interface. In addition, the military and several companies are also developing pathway synthetic vision systems. Therefore, there is significant need for research to be conducted toward development of tunnel concepts as usable parts of synthetic vision displays.

A considerable body of research exists demonstrating the effectiveness of pathway displays for horizontal and vertical guidance and enhancing situation awareness (e.g., Haskell \& Wickens, 1993; Williams, 2002). Many of these studies, however, failed to emulate the flight conditions that tunnel displays are postulated to ameliorate (e.g., curved approaches). Rather, they are often conducted using part-task simulations under conditions of low workload (e.g., straight-in approaches). Moreover, the tunnels were presented alone supplemented only by minimal flight instrumentation. Therefore, few studies (e.g., Schnell, Kwon, Merchant, \& Etherington, 2004, Theunissen, 1997) are available to guide tunnel and guidance symbology design for complex graphical displays, such as synthetic vision.

\subsection{Research Objective}

The objective of the present study was to examine the efficacy of four tunnel and three guidance symbology concepts for head-down synthetic vision displays. Two new pathways were conceptualized and evaluated that theoretically represented the best combination of current tunnel formats. Together, four tunnel (box tunnel, minimal "crows feet", dynamic "crows feet", dynamic pathway) concepts and a baseline concept (i.e., no tunnel) were evaluated using a "ball" guidance symbology. In addition, three guidance symbologies (ball, tadpole, follow-me-aircraft) were evaluated using the dynamic "crows feet" tunnel concept. Eight B-757 current major airline Captains flew the Sparks 16R visual arrival, curved approach under Category I instrument meteorological conditions (IMC); an approach of significant workload and difficulty, which is prohibited with today's equipage under such weather conditions. The scenarios were chosen to best evaluate the concepts under situations posited for a future commercial concept of operation for synthetic vision.

\subsection{Pilot Participants}

\section{METHOD}

Eight commercial pilots, who fly for major commercial airlines, participated in the experiment. All participants were HUD experienced and were rated B-757 Captains. The HUD requirement was to ensure familiarity with a velocity vector and guidance symbology. All participants also had logged flight time in "glass cockpits" (e.g., A-320; MD-11) other than the B-757; therefore, all participants were familiar with a primary flight display (PFD).

\subsection{Tunnel Concepts}

Four tunnel (box, minimal, dynamic "crows feet", dynamic pathway) and baseline (i.e., no tunnel) concepts were evaluated (see Figure 2). The "box" tunnel, a concept that is the subject of most of the tunnel research in the literature, consisted of a series of boxes connected at the corners to form a path within which the pilot flies. It was presented out to a length of $10 \mathrm{~nm}$, with no fading. The minimal tunnel concept consisted of a series of "crows feet" presented in each corner of a tunnel segment (essentially a truncated box). The tunnel presentation had 5 tunnel segments per nautical mile $(\mathrm{nm})$ with a total length of $3 \mathrm{~nm}$, which faded linearly to invisibility. The third concept, dynamic "crows feet", allowed the "crows feet" to grow as a function of path error. Therefore, the pilots are given feedback as to where they are in the tunnel and if they have flown outside the tunnel. The idea of the dynamic tunnel was that if the pilot is flying in the center of the tunnel, there should be the smallest amount of clutter. However, if there exists appreciable path error, the tunnel walls would "grow" to help the pilot gauge where the boundaries of the tunnel are. This helps to overcome a frequent criticism of "low clutter" tunnels. The fourth concept, dynamic pathway, was a variation of the dynamic "crows feet" concept in which the floor of the tunnel was presented at all times. For both the dynamic pathway and dynamic "crows feet", when the aircraft left the tunnel, the tunnel would change to a "trough" and resemble a box tunnel with the exception that the tunnel would open to "invite" the pilot back into the tunnel (Figure 3). All concepts and the baseline were paired with a navigation display with a Terrain Awareness and Warning System (TAWS). 

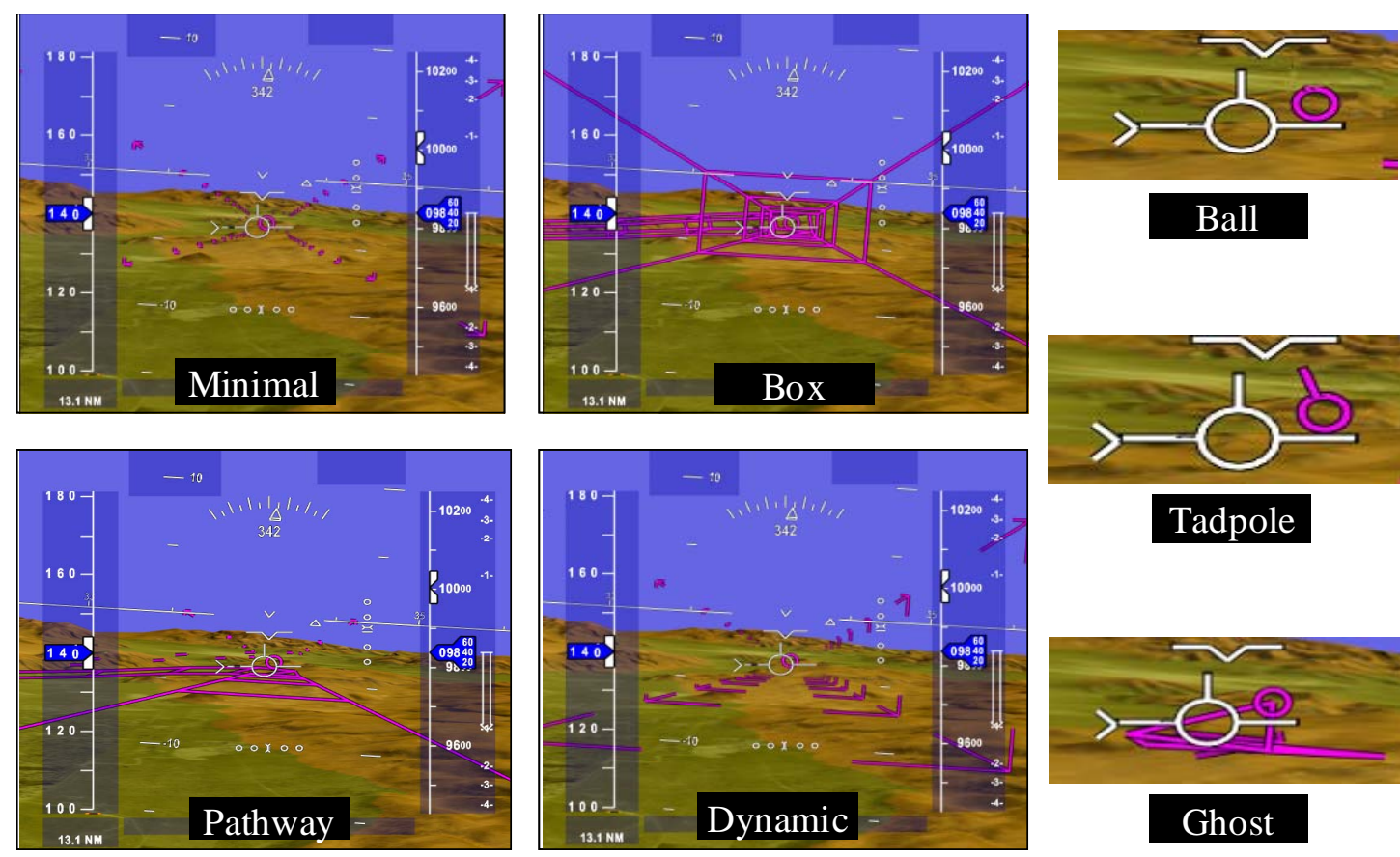

Ball

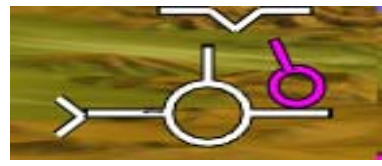

Tadpole

Figure 2. Tunnel and Guidance Symbology Concepts
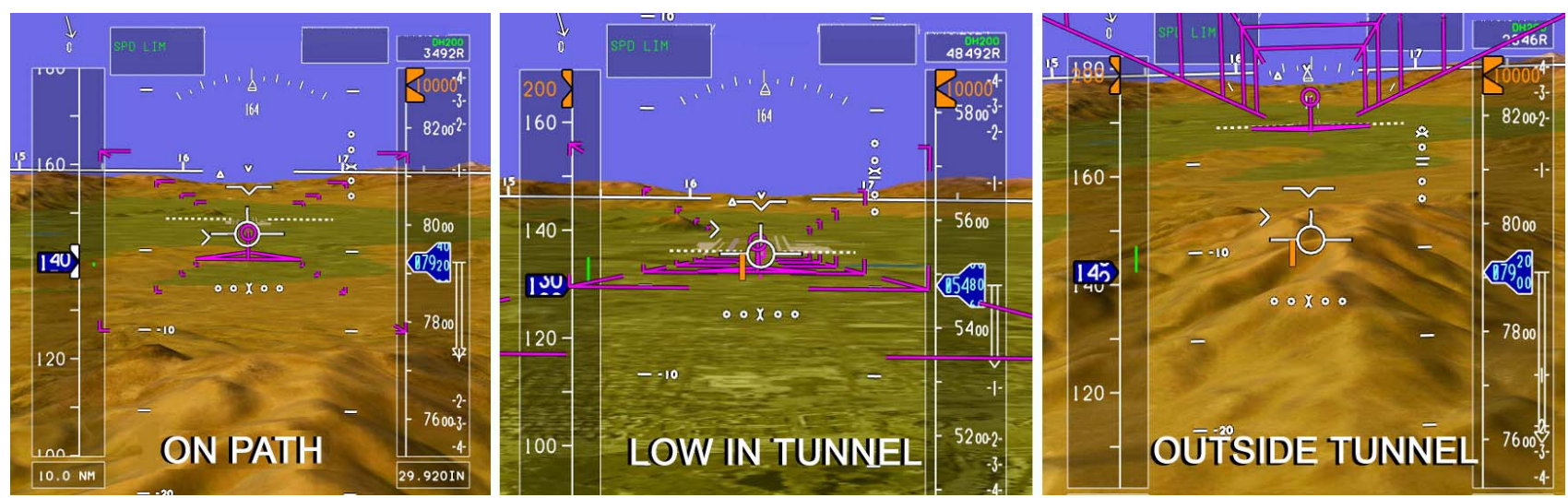

\subsection{Guidance Concepts}

Figure 3. Dynamic “Crow's Feet” Tunnel Concept

The guidance concepts were an integrated cue circle ("ball"), a "follow-me" aircraft ("ghost"), or a "tadpole" guidance symbol (Merrick \& Jeske, 1995). The control laws positioning the pitch and roll guidance commands were identical for each symbol - a modified pursuit guidance control law. The ball symbol was a laterally and vertically integrated guidance cue. The pursuit command was based on path positioned 30-seconds ahead of ownship on the centerline of the tunnel. Yaw, pitch, and roll attitude of the follow-me-aircraft reflected the track and flight path angles of the path at that lead position. The tadpole was the same as the integrated cue with added lateral track change information provided by the tail on the ball cue (Figure 2). The tadpole symbology is used in some military aircraft HUDs (e.g., F-16). 


\subsection{Experimental Task}

The evaluation task was the Sparks Visual Arrival to Runway 16R at Ren-Tahoe International Airport (RNO). Twenty-one experimental runs were completed during the experimental session (Figure 4), which were randomly assigned and partially factorial. The runs differed by the (1) initial starting position outside the tunnel, (2) the guidance symbology, and (3) task scenario. There were three initial starting positions that were randomly varied across trials to force the pilot to re-enter the tunnel on each run. The guidance symbology was also randomly assigned. However, it was only combined with the "dynamic crow's feet" tunnel concept. Finally, there were two subject tasks: (1) the nominal Sparks 16R Visual Approach, but flown under IMC, and (2) the "cut-the-corner" scenario in which the pilot was instructed by simulated Air Traffic Control (ATC) to fly "direct to" a waypoint on the final approach segment which required the pilot to leave the tunnel or flight path and then re-enter. The latter scenario required the pilot to utilize the navigation display (i.e., using the track predictor symbol to acquire the heading) and later to use the guidance symbology and velocity vector to re-enter the tunnel if available. All together, pilots randomly flew twenty-one runs as follows:

Minimal Tunnel with Ball nominal trial (2 experimental runs)

Minimal Tunnel with Ball "cut-the-corner" trial (1 experimental run)

Box Tunnel with Ball nominal trial (2 experimental runs)

Box Tunnel with Ball "cut-the-corner" trial (1 experimental run)

Dynamic Pathway with Ball nominal trial (2 experimental runs)

Dynamic Pathway with Ball "cut-the-corner" trial (1 experimental run)

Dynamic "Crow's Feet" with Ball nominal run (2 experimental runs)

Dynamic "Crow's Feet" with Ball "cut-the-corner" trial (1 experimental run)

Baseline with Ball nominal run (2 experimental runs)

Baseline with Ball "cut-the-corner" trial (1 experimental run)

Dynamic "Crow's Feet" with Tadpole nominal run (2 experimental runs)

Dynamic "Crow's Feet "with Tadpole "cut-the-corner" trial (1 experimental run)

Dynamic "Crow's Feet" with Follow-Me-Aircraft nominal run (2 experimental runs)

Dynamic "Crow's Feet" with Follow-Me-Aircraft "cut-the-corner" trial (1 experimental run)

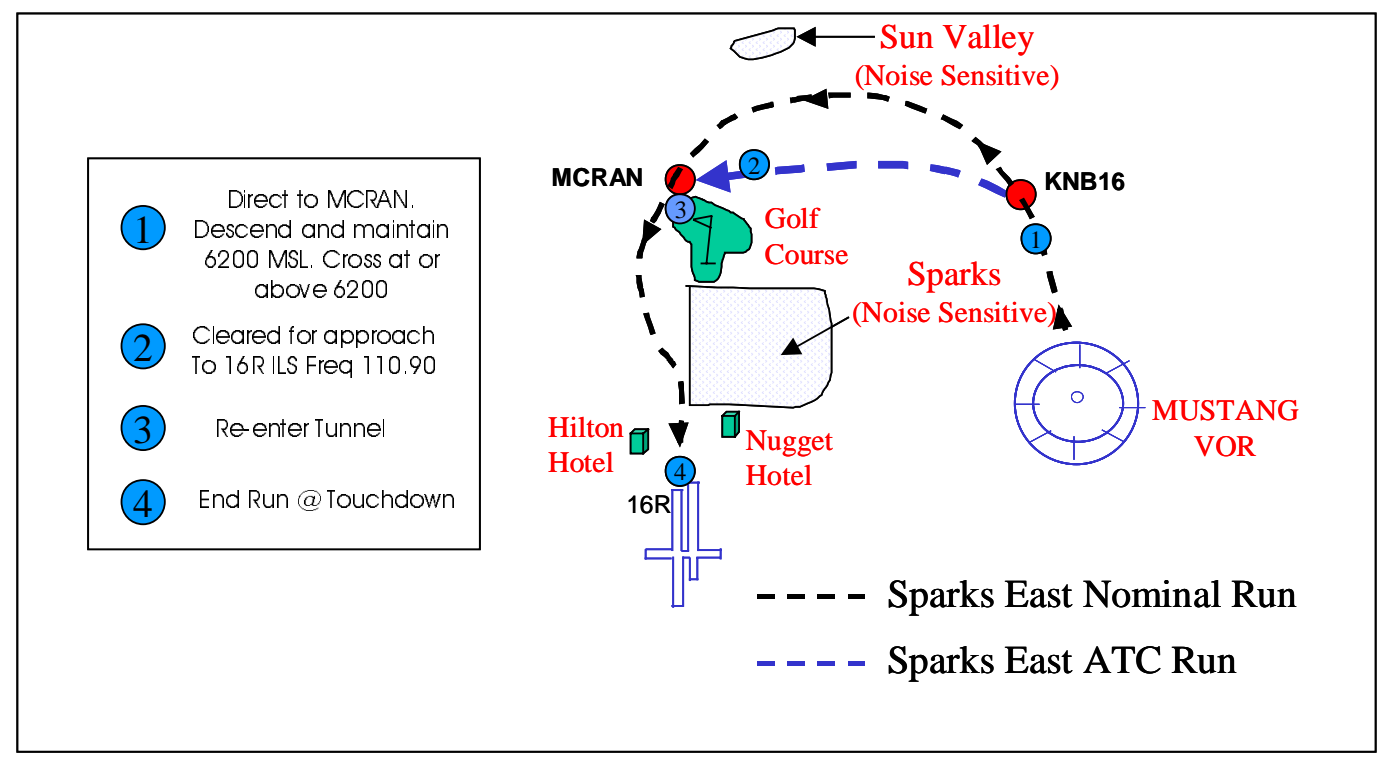

Figure 4. Nominal and "Cut-The-Corner" Scenarios 


\subsection{Simulation Facility}

The experiment was conducted in the Visual Imaging Simulator for Transport Aircraft Systems (VISTAS) III simulator at NASA Langley Research Center (Figure 5). The single pilot fixed based simulator consists of a $144^{\circ}$ by $30^{\circ}$ Out-The-Window (OTW) scene, a large field HDD and pilot input controls. The pilot controls in the VISTAS III workstation are a left side arm controller, left/right throttle controls, rudder pedals, toe brakes, and a voice recognition system (VRS). The VRS is a speaker-independent voice recognition system that provided a robust, rapidly reconfigurable pilot-vehicle interface. It was also used to provide automated alerts, warnings, and simulated ATC commands. The aircraft model was a B-757, and the speed target was 138 knots. Auto throttles were used, flaps were set to 30 degrees, and the landing gear was down.

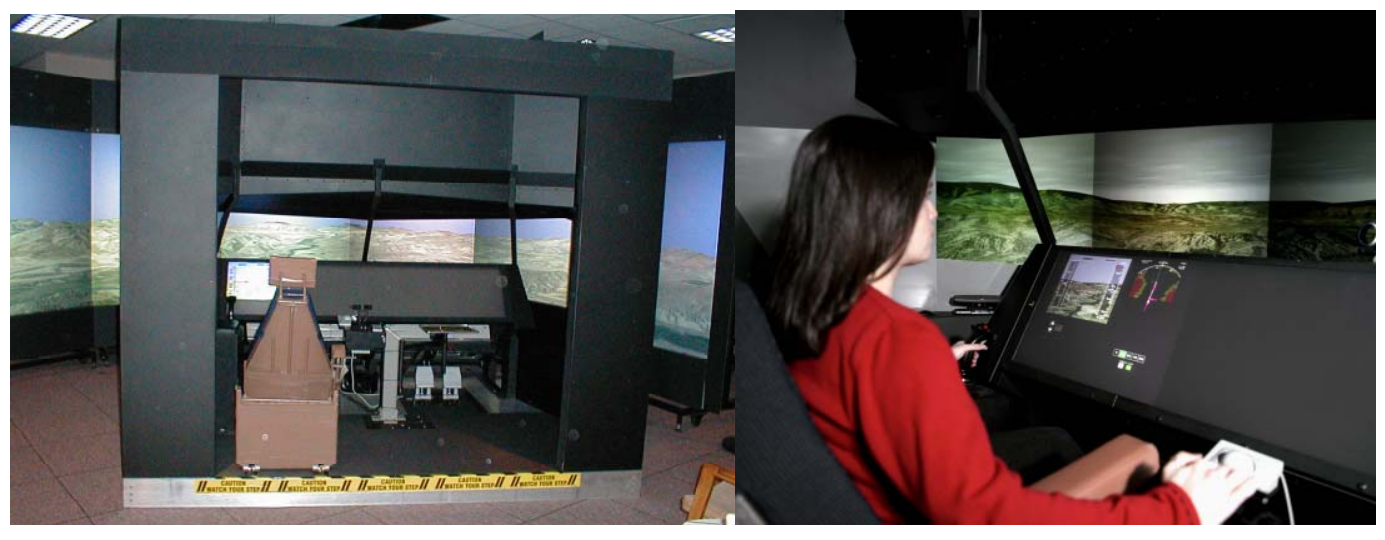

Figure 5. Visual Imaging Simulator for Transport Aircraft Systems (VISTAS) III

\section{RESULTS}

After each run, pilots were administered a run questionnaire consisting of the USAF Revised Workload Estimation Scale, Situation Awareness Rating Technique (SART), and six Likert-type (7-point) questions specific to tunnel evaluation. After the final experimental run, the Subjective Workload Dominance (SWORD) and Situation Awareness SWORD (SA-SWORD) scales were administered. Simple ANOVAs and Student-Newman-Keuls (SNK) post-hoc tests were performed. Alpha was set at .05 .

\subsection{USAF Workload Estimation Scale Results}

There was a significant effect found for tunnel with respect to mental workload, $F(4,28)=43.40$. The baseline condition (4.167) was rated significantly higher in workload than the four tunnel concepts. The minimal tunnel (3.167) was also rated significantly higher in workload than the box (2.583), dynamic pathway (2.542), and dynamic "crow's feet" (2.417), which did not differ from each other (Figure 6). No significant differences were found for workload between the guidance concepts $(\mathrm{p}>.05)$.

\subsection{Situation Awareness Rating Technique Results}

There was a significant effect found for tunnel with respect to the combined SART ratings, $F(4,28)=11.41$. The baseline (no tunnel) condition (3.417) was rated significantly lower in situation awareness (SA) than the four tunnel conditions. In addition, the minimal tunnel concept (5.083) was rated significantly lower than the box (7.167), dynamic pathway (7.458), and dynamic "crows feet" (7.542) which did not differ from each other (Figure 6).

For guidance symbology, an ANOVA found a significant main effect for SART, $F(2,14)=5.33$. The ball was rated significantly lower in SA than either the tadpole or follow-me-aircraft, which were not significantly different from one another. 


\subsection{SWORD Results}

An ANOVA found a significant main effect for Tunnel Type that was significant for the SWORD measure, $\mathrm{F}(4,28)$ $=340.519$. The SNK Post hoc test showed 3 distinct subgroups formed: 1) Dynamic and Pathway; 2) Full and Minimum; and 3) Baseline. The Dynamic and pathway tunnel concepts ranked as having the lowest workload and Baseline (no tunnel) the highest workload. The ranking from lowest workload to highest was: Dynamic "crow's feet", dynamic pathway, box tunnel, minimum tunnel, and baseline (no tunnel). No significant differences were found for guidance symbology for SWORD measure, $\mathrm{p}<.05$.

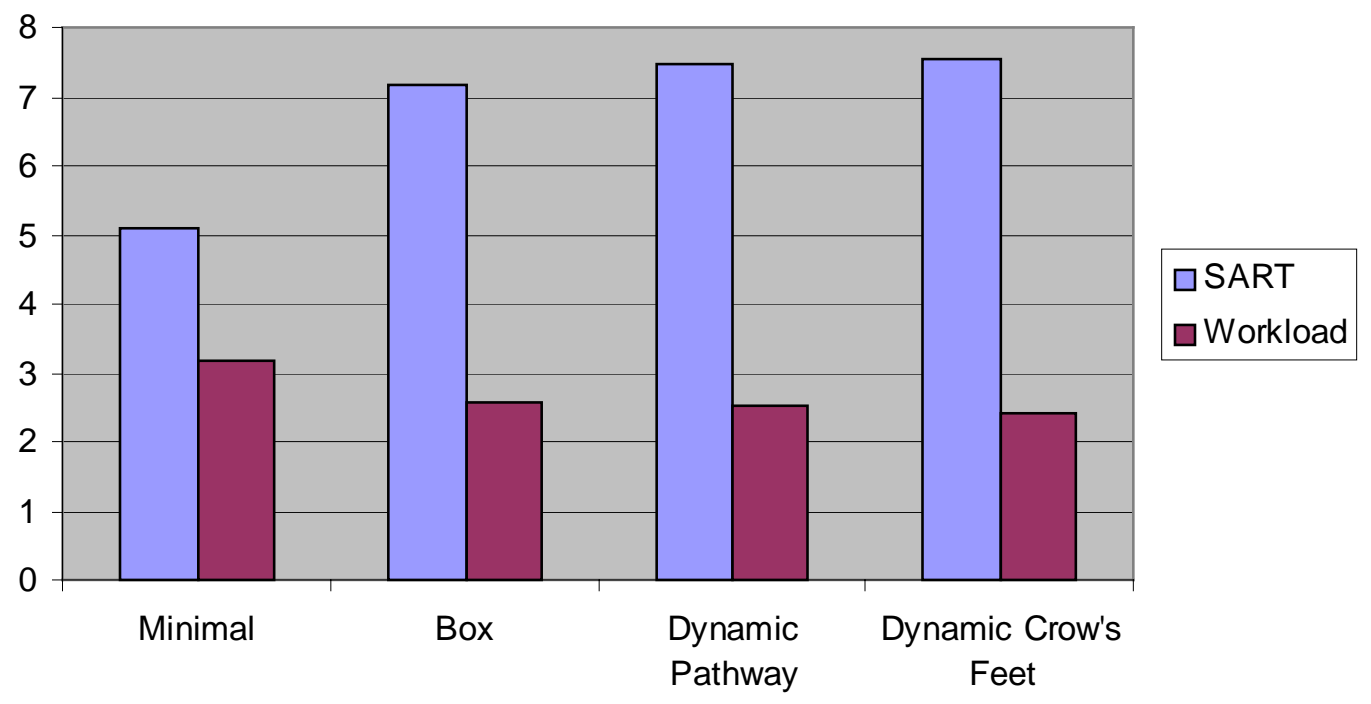

\subsection{SA-SWORD Results}

Figure 6. SART and Workload Estimation Scale Results

Overall, pilots ranked the dynamic "crow's feet" first in overall preference followed by dynamic pathway, box, and minimal tunnel. A distant fifth was the baseline condition which several pilots noted after flying the tunnel displays remarking, "how am I ever to go back to an EADI [electronic attitude direction indicator] after flying these displays?" An analysis of the results from the SA-SWORD confirmed this ranking. An ANOVA found a significant effect for tunnel, $\mathrm{F}(4,28)=84.369$ for the SA-SWORD paired comparison measure. Post hoc tests showed 4 distinct subgroups formed: 1) Dynamic; 2) Pathway; 3) Full and Minimum; and 4) Baseline. The Dynamic tunnel was ranked as having the greatest SA and Baseline (no tunnel) the worst

The analysis for SA-SWORD for guidance symbol type was significant for the SA-SWORD measure, F $(2,12)=$ 19.665. SNK Post hoc test showed 2 distinct subgroups formed: 1) Tadpole and Follow-me-aircraft \& 2) the Ball. The ranking from highest SA to lowest SA was: Tadpole, follow-me-aircraft and circle.

\subsection{Tunnel Run Questionnaire Results}

There was a significant effect found for several run questions asked. First, there was a significant effort found for SA, ("As I performed the task, my awareness of where I was in the tunnel was _.."), $\mathrm{F}(3,21)=22.07$. The minimal tunnel (2.833) was rated significantly lower in SA than the three other tunnel concepts. The dynamic pathway (5.00) was also rated significantly lower than the box (5.9167) and dynamic "crows feet" (6.0417), which did not differ from each other.

A second SA question asked was, "As I performed the task, my awareness of upcoming turns was __." An ANOVA found a significant effect for tunnel, $F(2,21)=5.06$. The minimal tunnel concept (3.292) was rated significantly lower than the dynamic "crow's feet" (5.208), dynamic pathway (5.208) and box (5.542) tunnel concepts. 
A third question asked, "As I performed the task, my level of flight path control and performance was ." A significant effect was found for display concepts (including baseline), F(4,28) = 27.05. The baseline condition (3.583) was rated significantly lower than the four tunnel concepts, which did not differ from each other.

A final question for tunnel evaluation was, "As I performed the task, my ability to intercept the path and re-enter the tunnel was __.". A significant effect was found for tunnel, $F(3,21)=17.54$. Participants rated the minimal tunnel concept (3.667) significantly lower than the dynamic pathway (5.083), dynamic "crow's feet" (5.333), and box tunnel (5.333) concepts. The three tunnel concepts were not statistically different from each other.

\subsection{Guidance Symbology Run Questionnaire Results}

One of the Likert-type run questions asked of each evaluation pilot was, "As I performed the task, my ability to anticipate flight path changes using the guidance symbology was ___." An ANOVA found a main effect for guidance symbology, $\mathrm{F}(2,14)=5.68, \underline{\mathrm{p}}<.01$. Based on the SNK post-hoc test, pilots rated the ball (4.0) significantly lower that both the tadpole (5.25) and follow-me-aircraft (5.25) guidance symbologies.

As was done for the tunnel concepts, subjective ratings of flight path control were evaluated for guidance symbology ("As I performed the task, my level of flight path control and performance was ."). An ANOVA found a significant effect for guidance symbology type, $\mathrm{F}(2,14)=4.56, \mathrm{p}<.05$. The SNK post-hoc test showed that pilots rated the ball (3.917) significantly lower than the tadpole (5.25) and follow-me-aircraft (5.292).

\subsection{Flight Path Control}

Flight path control was analyzed for the nominal task run by root-mean-squared tracking error (RMSE). Because guidance symbology may confound flight path accuracy, the results were analyzed as symbology-tunnel combinations yielding six display concepts plus the baseline (i.e., no tunnel, ball symbology). An ANOVA found a significant effect for lateral RMSE across guidance symbology-tunnel combinations, $\mathrm{F}(6,42)=6.839$ (Figure 7). The baseline condition was found to be significantly worse for lateral flight path control (132.63 feet). No statistical differences were found for lateral RMSE between the three tunnel concepts regardless of the guidance symbology. No significant differences were found for vertical path error across the display concepts including the baseline condition ( $\mathrm{p}>.05)$. Finally, no differences were found between the three guidance symbologies for RMSE.

\subsection{Tunnel Semi-Structured Interview Results}

A semi-structured interview was conducted after the final experimental run. A number of Likert (1 to 7) questions were asked but space does not allow a detailed summary of the results. However, several interesting results were found. For example, although there was no significant difference in rating for effectiveness of tunnels for straight path segments, pilots rated the minimal tunnel concept (4.00) significantly less effective for curved path segments than the box (5.4), dynamic pathway (6.2), and dynamic "crows feet" (6.4), F(3,28) = 10.09, p <.05 (Figure 8). Another interesting finding was that pilots rated the baseline (5.6) and minimal tunnel (4.5) concepts to have significantly more workload to intercept the path during the "cut-the-corner" scenario, $F(3,35)=43.56, \mathrm{p}<.001$. There were no statistical differences between the box (3.0), dynamic pathway (1.9) and dynamic "crows feet" (1.8) concepts.

Overall, pilots ranked order their preferences as dynamic "crow's feet", dynamic pathway, box, minimal, and baseline (no-tunnel). Although most pilots stated that the preference between the dynamic tunnel concepts was minor, several thought that the presence of the tunnel floor in the dynamic pathway concept generated too much clutter compared to the dynamic "crow's feet". The minimal tunnel concept was reported to provide too little information but many pilots felt that their opinion would change if the task required them to use a head-up display (cf. Kramer, Prinzel, Arthur, Bailey, 2004). The box tunnel concept was also reported to be poor compared to the dynamic tunnel concepts mostly because of concerns of clutter. This was particularly acute on final approach when the box tunnel obscured the synthetic runway even at unity minification.

\section{9 Guidance Symbology Semi-Structured Interview Results}

An ANOVA was performed on pilot responses to the effectiveness of guidance symbology for situation awareness and flight path control for both straight and curved path segments (Figure 9). A significant result was found only for the 
curved / banked flight path segments, $\mathrm{F}(2,21)=36.56, \underline{\mathrm{p}}<.0001$. Pilots rated the ball (3.5) significantly worse than either the tadpole (6.10) or follow-me-aircraft (6.25). However, no significant differences were found between the ball (5.65), tadpole (6.10) and follow-me-aircraft (6.10) for the straight path segments, $F(2,21)=2.49, \underline{p}>.05$.

\section{Approach RMS Path Error}

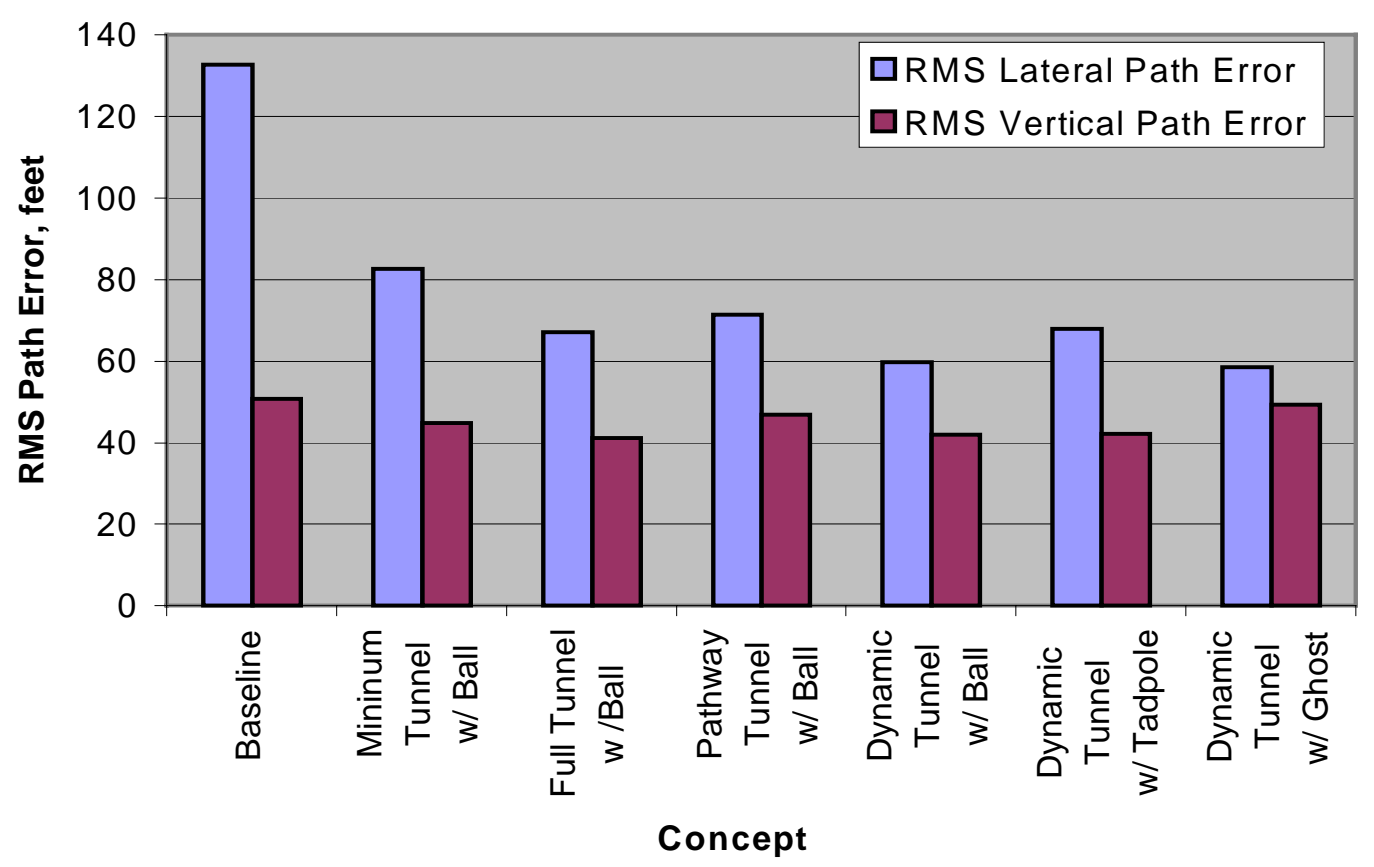

Figure 7. Approach RMS Path Error

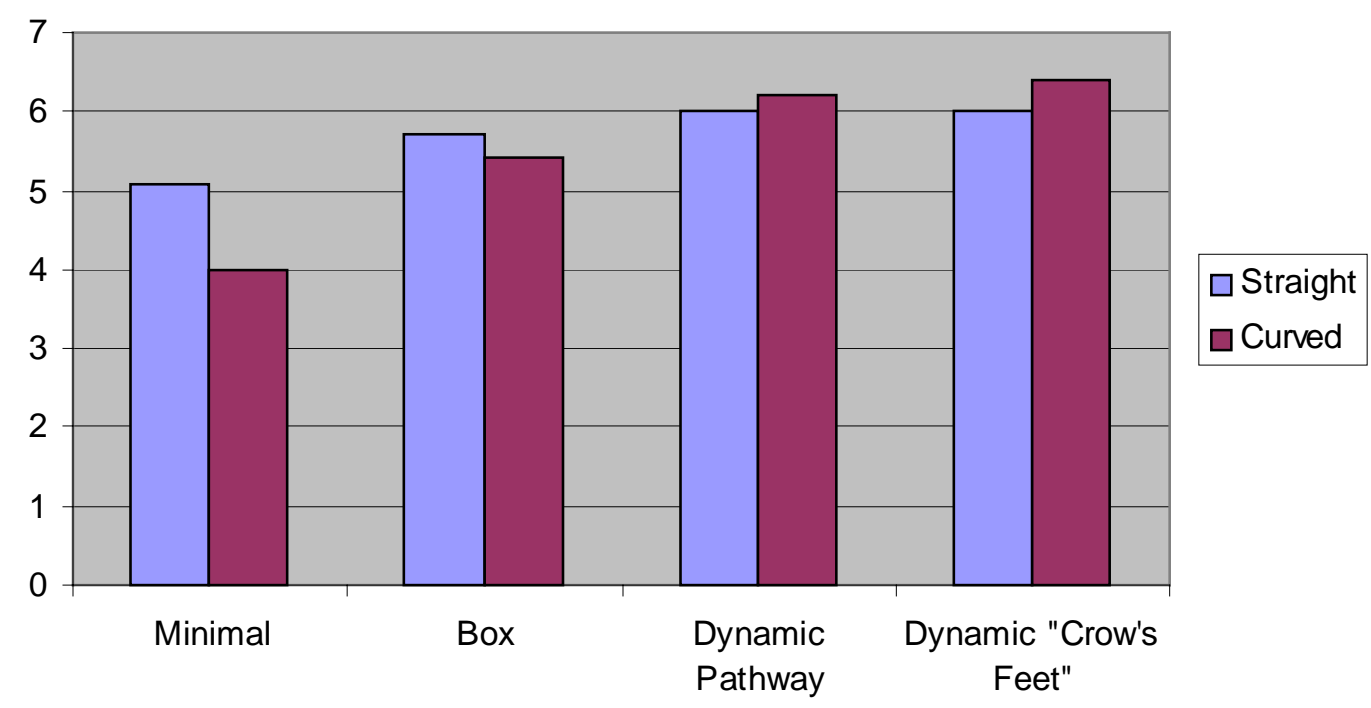

Figure 8. Effectiveness of Tunnel Concepts for Flight Path Segments 


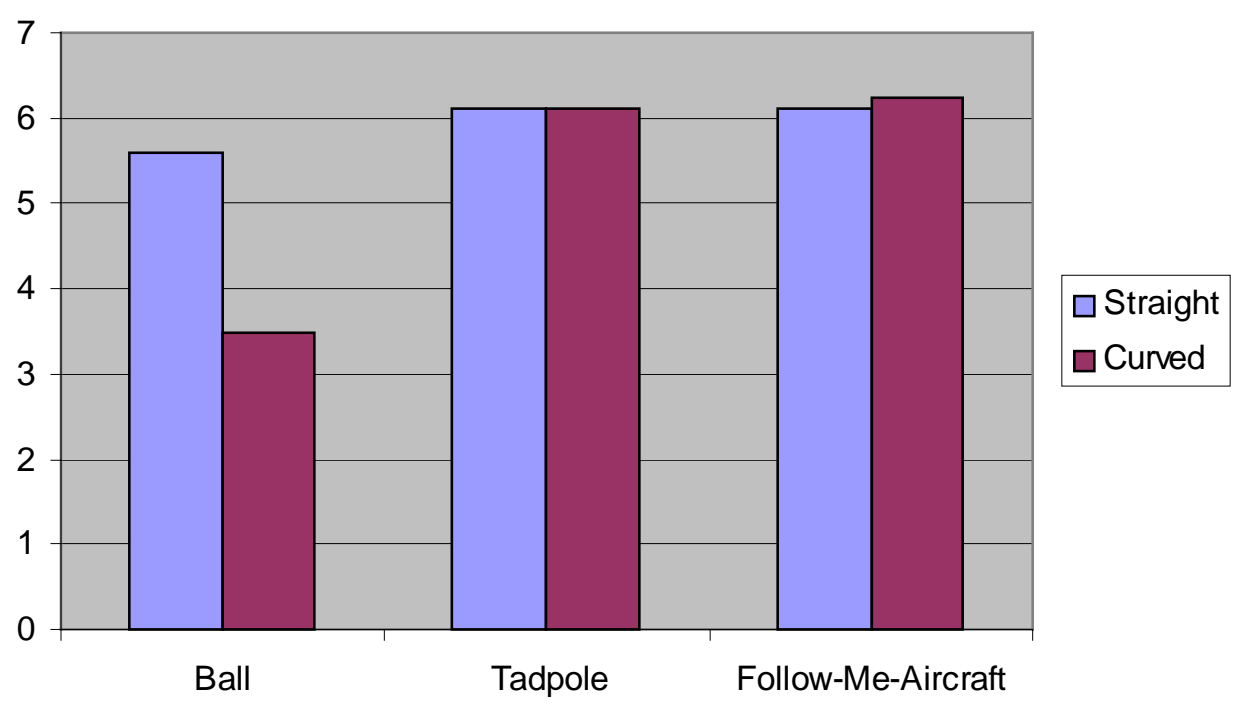

Figure 9. Effectiveness of Guidance Symbology for Flight Path Segments

Another interesting finding was the percentage of situation awareness enhancement that the tunnel provides compared to just flying with one of the three guidance symbologies. Overall, pilots rated the ball to provide only $20 \%$ of their situation awareness, but $70 \%$ for the tadpole and follow-me-aircraft guidance symbologies. Said another way, the dynamic "crow's feet" tunnel provides an additional $80 \%$ situation awareness enhancement when paired with a ball compared to only $30 \%$ when paired with tadpole or follow-me-aircraft guidance symbology.

\section{DISCUSSION}

An experiment was conducted to examine the efficacy of different tunnel and guidance symbology concepts for head-down synthetic vision displays. The results indicated that the presence of a tunnel had a marginal effect on enhancing path control performance for the head-down display compared to the baseline (no tunnel w/ ball guidance). Further, no significant differences were found for path control performance between the four tunnel concepts. Despite this, statistically significant differences were found for pilot ratings for situation awareness and workload. Overall, pilots rated the tunnel concepts to be significantly better in terms of workload and situation awareness compared to not having a tunnel present. When just the tunnel concepts are considered, the minimal tunnel concept was consistently rated poorer followed by the box tunnel concept compared to the dynamic tunnel concepts. The reasons are different for the two tunnel concepts. The minimal tunnel was found to be poor for situation awareness because it was difficult to accurately determine where you were in the tunnel. However, pilots did note that the presence of the guidance symbology and path deviation indicators significantly reduce this problem. Furthermore, all pilots remarked that the minimal tunnel might be optimal for a HUD where issues of clutter are of particular concern compared to the PFD. The box tunnel, in contrast, was rated poorer because of concerns of clutter especially on final approach. Although it was fairly easy to determine where they were in the tunnel, the advantage was negated because the tunnel obscured the synthetic terrain. For these reasons, the evaluation pilots preferred the dynamic tunnel concepts for a head-down synthetic vision display.

Overall, the dynamic pathway was rated very high for situation awareness, but several pilots reported that the presence of the tunnel floor ("railroad track") was unnecessary when compared to the dynamic "crow's feet" tunnel. Therefore, although preferred to the minimal and box tunnel concepts, the dynamic "crow's feet" was reported to provide all the advantages of the dynamic pathway with less clutter. All pilots remarked that the dynamic quality of the tunnel was useful to determine exact position within the tunnel and the "trough" effect when outside the tunnel made it very easy to re-enter the tunnel. However, most pilots thought that the tunnel might have been too dynamic and somewhat distracting. Therefore, the algorithm for controlling the dynamic "crow's feet" tunnel growth will be optimized to eliminate this issue. 
For guidance symbology, the ball was found to be adequate but the tadpole provided more information than the ball without an increase in clutter. The follow-me-aircraft, on the other hand, was rated best overall for SA and workload because it gave yaw, pitch, and roll information compared to just track change information provided by the tadpole. When comparison was made when paired with the dynamic "crow's feet" concept, the differences between the guidance symbology concepts were more apparent. Pilots reported that the tunnel enhanced their situation awareness by $80 \%$ when paired with the ball compared to only $30 \%$ for the tadpole and follow-me-aircraft. Pilots did note that the ball coupled with a dynamic "crow's feet" tunnel was very acceptable for flight path control and situation awareness. However, the tadpole and follow-me-aircraft conveyed important preview information not provided for by the tunnel concepts. Taken together, the follow-me-aircraft and dynamic "crow's feet" tunnel concepts were rated to be the best candidates for future head-down synthetic vision displays.

Research is currently being conducted at NASA Langley to enhance the dynamic tunnel concept with tactical and strategic display information to help realize 4D RNP capability. A flight test evaluation is anticipated in 2004 to examine a synthetic vision system that integrates the enabling technologies (Runway Incursion Prevention System, Synthetic Vision Sensors, and Database Integrity Monitoring Equipment) with synthetic vision displays. The research will focus on the integration of runway incursion prevention technologies, surface map displays, integrity monitoring, enhanced vision sensors, SVS navigation displays, and enhanced synthetic vision head-down and HUD displays. Together, such a synthetic vision system may considerably help meet national aeronautic goals to "reduce the fatal accident rate by a factor of 5" and supplement efforts to "double the capacity of the aviation system", both with 10 years (NASA, 2001).

\section{REFERENCES}

Arthur, J.J., Prinzel, L.J., Kramer, L.J., Bailey, R.E., and Parrish, R.V. (2003). CFIT Prevention Using Synthetic Vision. SPIE. In J.G. Verly (Ed.), Proceedings of SPIE, Enhanced and Synthetic Vision 2003, 5081-16, 146-157.

Bennett, K.B., \& Flach, J.M. (1994). When automation fails.... Human performance in automated systems: Current research and trends (pp. 229-234). Hillsdale, NJ: Lawrence Erlbaum Associates.

Boeing (1998). Statistical summary of commercial jet aircraft accidents, Worldwide Operations, 1959-1997. Seattle, WA: Airplane Safety Engineering, Boeing Commercial Airplane Group

Enders, J.H., Dodd, R., Tarrel, R., Khatwa, R., Roelen, A.L.C., \& Karwal, A.K. (1996). Airport safety: A study of accidents and available approach-and-landing aids. Flight Safety Digest, 1996(3), 1-36.

Haskell, I.D., \& Wickens, C.D. (1993). Two- and three-dimensional displays for aviation: A theoretical and empirical comparison. International Journal of Aviation Psychology, 3, 87-109

Hemm, R.V. (2000). Benefit estimates of synthetic vision technology. NASA Langley Research Center Contractor Report NS002S1.

Kramer, L.J., Prinzel, L.J., Bailey, R.E., \& Arthur, J.J. (2003). Synthetic vision enhances situation awareness and RNP capabilities for terrain-challenged approaches. Proceedings of the American Institute of Aeronautics and Astronautics Third Aviation Technology, Integration, and Operations Technical Forum, AIAA 2003-6814, 1-11.

Merrick, V.K., \& Jeske, J.A., "Flight Path Synthesis and HUD Scaling for V/STOL Terminal Area Operations," NASA TM110348, April 1995.

National Aeronautics and Space Administration (2001). Aerospace Technology Enterprise. Washington, D.C.: NASA.

Prinzel, L.J., Comstock, J.R., Glaab, L.J., Kramer, L.J., Arthur, J.J., \& Barry, J.S. (2004). The efficacy of head-down and head-up synthetic vision display concepts for retro- and forward-fit of commercial aircraft. International Journal of Aviation Psychology, 14, 53-73.

Prinzel, L.J., Hughes, M.F., Arthur, J.J., Kramer, L.J., Glaab, L.J., Bailey, R.E., Parrish, R.V., \& Uenking, M.D. (2003). Synthetic Vision CFIT Experiments for GA and Commercial Aircraft: "A Picture Is Worth A Thousand Lives". Proceedings of the Human Factors \& Ergonomics Society, 47, 164-168.

Prinzel, L.J., Kramer, L.J., Bailey, R., Hughes, M., \& Comstock, R. (2002). NASA Eagle-Vail Synthetic Vision Flight Test. Proceedings of the Human Factors and Ergonomics Society $46^{\text {th }}$ Annual Meeting, 46.135-139

Prinzel, L.J., Kramer, L.J., Comstock, J.R., Bailey, R.E., Hughes, M.F., \& Parrish, R.V. (2002). NASA synthetic vision EGE flight test. Proceedings of the Annual Human Factors and Ergonomics Meeting, 46, 135-139.

Schnell, T., Kwon, Y, Merchant, S., \& Etherington, T. (2004). Improved flight technical performance in flight decks equipped with synthetic vision information system displays. International Journal of Aviation Psychology, 14, 79-102.

Theunissen, E.R. (1997). Integrated design of a man-machine interface for 4-D navigation. Delft, Netherlands: Delft University Press.

Wiener, E. L. (1977). Controlled flight into terrain accidents: System-induced errors. Human Factors, 19, 171-181.

Williams, D., Waller, M., Koelling, J., Burdette, D., Doyle, T., Capron, W., Barry, J., \& Gifford, R. (2001). Concept of operations for commercial and business aircraft synthetic vision systems. NASA Langley Research Center: NASA Technical Memorandum TM-2001-211058.

Williams, K.W. (2002). Impact of aviation highway-in-the-sky displays on pilot situation awareness. Human Factors, 44, 18-27. 